of youths, it is essential to recall that growing boys and girls require comparatively more food than adults because it is necessary to store up energy required for growth and at the same time to make good the daily loss of energy. In this connection, it is interesting to recall that tall, lean boys and girls require more food than short, fat persons of equal weight. Also, that natural foods yield the essentials required to replace the energy expended, and for the repair and growth of the body. The cheaper foods, such as bread, margarine, porridge, milk, herrings, cheese, beans, onions, cabbage, oranges and cheaper cuts of beef, provide all the requisite nourishment, and probably better health than is derived from more highly flevored and expensive foods which only artificially stimulate the appetite.

The great question today in the health problem involved in war industries, is not wholly whether the workers are standing, without evident injury, the strain of overtime, long shifts, Sunday or night work employment, but whether they can stand it for a long period; and, secondly, whether the toll to be collected later in the ill health, lack of efficiency, and in the development of permanent organic disease, can, in any measure, be compensated by the temporary increase in income and wages for any overtime employment. Physiology has very definite and positive findings on all these matters. Any other basis of meeting the issue is shifting and unstable.

\section{SOME RELATIONS OF EXERCISE TO} NUTRITION.*

By George Van Ness Dearborn, M.D., Cambridge, Mass.,

Instructor in Psychology and Education, Sargent Normal School, Cambridge; Psychologist and Physiologist to the Forsyth Dental Infirmary for Children, Boston; etc.

\section{CONTENTS.}

I. Too Littrle Physical Fxertion.

(a) Weakness of the Digestive Musculature.

(b) Atony of the Autonomic Nervous System.

(c) Weakness of Digestive Secretion.

(d) Iowering of the Food-Appetite.

(e) Obesity.

(f) Constipation.

Exercise during Gastric Digestion.

II. FOOD-SUGAR.

III. Diet for Ample Physical Exertion ("TrainING.")

(a) Adequate in Amount, but Not Excessive.

(b) Abundance of Water.

*Advance material from a forthcoming work, "The Physiology of (c) No Intestinal Irritants.

(d) Sugar in Abundance.

(e) Four Daily Meals.

(f) Coffee and Tea and Cocoa.

(g) Tobacco.

$(h)$ Alcohol and Strychnin Forbidden. Adrenin.

IV. TOO MUch Physical ExeRTion.

LATAN NESS.

LUMBERMEN vs. VARSITY "HERo."

IN discussing the relations of bodily exercise to nutrition we are on the foundation-stones of the physiology of exercise, for this phase of the physical life, of course, underlies and conditions all the rest. Our bodies are primarily physiochemic, self-repairing machines, and require continual renewal as well as a continual supply of energy-liberating materials. On many phases of nutrition the general public needs precise and authoritative information, and for practical purposes the motto of this more or less unconscious demand is economy-economy of several things of prime importance and value to the average individual. It will be one of the purposes of this paper to show that exercise is the natural regulator of the nutritive functions, and how this control is exerted in the interests of economy and efficiency. The medical practitioner may care to have things "recalled" to him.

The most important phase of the subject is that wherein we have to deal with the effects of "too little exercise."

We may sum up the whole effect of too little exercise upon nutrition in one short word, "atony" - a lack of tone, of vigor, of activity ; a condition just the opposite from that of tonicity, where there is a normal condition of tone or functional tension.

We will consider the effects of too little exercise on nutrition under six heads :

The first thing to notice is that the vigor of the muscles of digestion is lessened, this being really a sympathetic effect with the skeletal or voluntary muscles. The muscular vigor of the digestive musculature is too small, and this condition, known as an atonic condition of the digestive apparatus, is the most serious in the muscles of the alimentary canal. There are two fundamental things going on in the alimentary canal in the process of nutrition. One is an elaborate set of chemical reactions comprised under the technical term of "hydrolysis" (simplification due to the enzymic absorption of water), and another set of more mechanical changes due to muscular movements. It is al- 
most impossible to think of food passing down about thirty feet of distorted and convoluted alimentary canal without muscular movements to move it along its course. A most serious condition is paralysis in the intestines. There are longitudinal and circular muscle fibers in the intestine, and we already know of their indispensable importance. Anything which, owing to the principle of sympathy, lowers the tone of the skeletal muscles will also lower the tone of the smooth muscles of the viscera. However much food a man can digest and eat, if he is lying in bed and his skeletal muscles are in consequence weak and flaccid, his digestive processes will also be weak, because his smooth muscles will also take part in the general condition of atony. Thus, the condition of the skeletal muscles is of much nutritional importance. We know that when we invigorate a voluntary muscle by voluntary exercise, we also invigorate the smooth muscle and increase its tone and vigor, especially in the viscera and in the arteries.

Recently we have learned from the researches of various people, including those by Caroline McGill, how very closely allied are the crossstriated and the smooth muscles. In fact, the change from a smooth muscle to a cross-striated muscle takes place very easily in certain animals. Conversely in a way, anything which tends to decrease the tonus of the skeletal or voluntary muscles also affects the smooth musculature, and this effect can be seen in the smooth muscle fibers of the intestines. Here is a sympathetic degenerating atony of the muscle fibers of the intestines from a lack of all-round general exercise. You see a typical illustration of this condition in the case of convalescence from an exhausting disease. The person has lain abed for weeks, perhaps months, and has been prevented from taking any exercise. The vigor of his digestive process at the end of that period is very weak, even if he is eating very little food. In some severe thoracic diseases, it is true, the person afflicted is apt to eat even twice as much as under ordinary healthy conditions, and the food, notwithstanding, may be digested. But his digestive apparatus may be very .weak purely from sympathy with the decreased vigor of the voluntary muscles, for the smooth muscles have developed sympathetically with the skeletal muscles.

Here we may be pardoned, perhaps, if we repeat from the author's "Certain Further Fac- tors in the Physiology of Euphoria"* a page devoted to the motor action of the villi in nutrition :-

Passing now to the mechanism and process of intestinal absorption we see in the neuro-musculo-glandular mechanism of the villi and the valvulæ conniventes a much more competent and actively adaptable apparatus than has been disclosed heretofore. In general terms the presence of muscle means the active adaptation of an organ to conditions outside itself, for example, in the absorptive organs mentioned as well as in the spleen and ovary.

Whatever may be the adaptive movements of the valvulæ, the villi are the chief immediate organs of food absorption from the intestine. There are about four million of these organs in the human. They are irregular but in general finger-shaped organs varying in length from 0.5 to 3.0 millimeters. Their combined surface area, situated as they are on the valvulæ conniventes, increases the absorptive area of the intestine at least an hundred fold over what it would be were the gut a smooth-walled tube instead of one partly filled at times by these organs. The villus is a complex little organ for, besides its versatile and essential wall of columnar epithelium, it consists of smooth muscle, autonomic nerves, a conspicuous central lymphatic ("lacteal"), blood vessels, leucocytes, and connective tissue. It would be pedantic to venture conjecture as to the exact modus operandi of such a mechanism. Fat, however, is the only alimentary principle which is mechanically conveyed from the midst of the epithelial cells (where it is apparently synthesized from the fatty acids and glycerin) to the central lymphatic. The chief function of this "lacteal," so far as known, is to receive the fat globules and to forward them into the circulation proper via the thoracic duct. Howell says (1913) : "The mechanism of absorption remains unexplained." It is, however, extremely probable that the neuromuscular mechanism of the villus has, as part of its function at least, the compression of the villus under nervous requisition for more fat from other parts of the body. On this basis the villus is understandable as in part a minute reservoir of adipose material, perhaps indeed chiefly for the greatly variable use of the nervous system, nerve-cells (chromatin) and nerve fibers (myelin) alike. They clearly make up by their number what each lacks in size.

*Psychological Review, xxi, 3, May, 1914, illst'd, pp. 166-188, 
The first effect, then, of too little exercise upon nutrition is that of a direct effect upon the muscles, and in this particular case, the digestive musculature.

In the second place, we must consider the effect of too little exereise upon nutrition through the nervous system. The central nervous system lacks tone as well as do the muscles when there is too little exercise. This lack of tone in the central nervous system helps to decrease the requisite tone in the digestive organs. A second effect, then, of atony, is a lack of tone in the nerve centers which have to do with the movements and the secretions of the digestive organs. There is a reflex and sympathetic control of the digestive apparatus, from the autonomic and from the central nervous system. When the nerve cells are not up to their normal standard, there is a lack of tone and invigoration from the spinal cord, and the sympathetic system fails to send impulses. The nerve cells are not up to their usual efficiency, perhaps because of a lessening of the chromatin granules always found in the cytoplasm of nerve cells. The lack of exercise affects the nerve centers as well as the muscles, and so the movements of the alimentary canal are less accurate and less vigorous, and, meanwhile, nerve stimulation itself is less vigorous to those parts.

Again, the secretions of the alimentary canal are less active and vigorous, and they are deficient in quantity, owing to the lack of allround bodily exercise. No one has ever shown, so far as the writer knows, that these products are qualitatively changed.

A third effect of too little exercise upon nutrition is inadequate or "poor," appetite. Too little exercise lowers the appetite below the normal, or else the appetite is an artificial one, which is worse. If, owing to the sluggishness of the circulation and the atony of the muscles, the appetite be allowed to drop too low, there is a decreased demand for food, and the body is not nourished properly. The appetite for food and drink, in the case of the normal man doing little work, is for little food, while the man doing a great deal of work needs, requires, and wishes much food. In the normal, pristine individual that is the normal condition, and it is only because man has grown into the habit of not adapting his food to the amount of his muscular work, that the condition or ratio is not always in evidence. The normal appetite is the proper indicator of the amount of food required by the individual. On the other hand, if the appetite is kept up artificially, the person eats a useless lot of food. This leads to a "uric-acid diathesis" and to obesity, and there is a large amount of nitrogenous waste materials that must be got rid of somehow. These waste materials continually circulate in the blood and are oxidized and katabolized directly from the circulation. The nitrogen comes from the protein sub. stances eaten, and, some think, is converted into uric acid. This acid then circulates in the blood, and causes pains in the joints, etc.-things known to the medical man of a generation ago under the term of "uric acid diathesis." In this condition there is an excess of protein ingested, due to an artificial appetite and the eating of large amounts of general food. The muscles do not use up the protein, as there is a small demand for nitrogenous food material because of a lack of exercise. It is supposed by some, that an excess of nitrogenous material passing for long through the kidneys, gives rise to some condition allied to Bright's disease. Over-stimulation of the kidneys might very reasonably give rise to interstitial nephritis, under conditions of too little flushing out.

Another effect of too little exercise upon nutrition is seen in the condition of obesity.

Perhaps it may be forgiven the writer if here he quotes seven paragraphs from an article ${ }^{1}$ on overweight, which suggests the sereaming wrong and the utter needlessness of this condition of overweight:

Physiological obesity can always be reduced (as long as the kidneys, heart, and the other vital organs are sound and can stand the pressure) by a greatly increased amount of systematic exercise and by a reduction in the intake of food-the latter the more important. Increase the outgo of energy from the organism and decrease the intake of energy into the organism, and it is always possible to reduce truly physiological obesity. This is one place where a contrast appears between pathological and physiological corpulence. In many cases of physiological obesity the persons have weak hearts, stomachs, or kidneys, and these weaknesses properly prevent either a rapid decrease in the food or a rapid increase in the amount of fat-destroying exercise. Then, too, some unstable nervous systems cannot stand a quick decrease in the energy value of food, so that it is

1 Dearborn, G. V. N.: "Get Fat and-Die," Interstate Medical Journal, Vol. xxiv, No. 2, February, 1917. 
not safe to decrease the food supply too rapidly.

Most of the false obesity cures bring about their effects, if there be any at all, by actually disturbing and deranging the process of digestion by a distinct pathological change, while they do not attempt to remove the cause of the superfluous amount of fat.

One way to remove the cause of physiological obesity is to reduce the metabolism of food. Give the person foods that are "filling," such as bran bread and fruits and top-of-the-ground vegetables, whose tissue-forming value is small, very small, as far as calories of energy are concerned. Cellulose and water! Another method of bringing about the same result is to drink a cup of sweet, weak coffee or to eat dessert or a few pieces of candy first, so that plainer foods become tame and unpleasant to the taste, and easily foregone. Some find it easier to omit all food one day, or even two, in every week, water being meanwhile freely taken.

Because the method puts one on his own feet and makes him master of himself, perhaps the most important way in which to reduce diet is to use continuous will power of restraint. Very few really fat people have sufficient will power, however, month after month, to reduce the diet in a systematic and scientific manner. Most of them, lacking the necessary strength thus to lessen their food, go to sanatoriums and there are put under strict surveillance as regards everything pertaining to their diet. For quite a percentage of far overweighted persons it is either this heroic treatment, passively endured, or nothing.

One thing is certain. For the far larger number of persons overweight who do not find it expedient to change their actual daily occupations from a low plane of energy expense (via muscular exercise) to a higher, it is quite futile to expect weight reduction by bodily work alone, whether in a fine gymnasium, on the farm, or elsewhere. The commoner experience of middleaged women and men who seek thus to normalize themselves hygienically and cosmetically, of course, is to gain weight rather than lose after the first week or so. They actually improve their general condition, as well as their food appetite, so much by the daily hour or two of un. wonted highly enjoyable general exercise that their metabolism is raised so that they "put on" fat. They take just enough exercise to normalize nutrition, but not nearly enough to burn up any tissue fat. But forty-eight hours a week of labor for each of the four weeks of several months would do it! And it is thus, and only thus for the most part, that the million retain the semblance of the properly human form, for their diet, for the most part, otherwise would be excessive.

Those who have fatness thrust upon them are the adipose victims of circumstances. Some of these are, of necessity, engaged in over-sedentary occupations; some are helpless cripples; some are ignorant; some are indifferent-i.e., of swinish disposition; some are wise, but weak-willed; and some are strong-willed enough, but foolish or perhaps indifferent to the length of life or to the full measure of physical and moral manhood or womanhood. But with this, although a considerable class of the obese, we need not here concern ourselves, for the scientific conditions are like unto those of the persons who achieve fatness-although, humanly speaking, far harder, because less often relieved. Yet these, too, might readily be free-free of being inefficient; free of suffering unduly in a warm atmosphere year after year; of manifold personal dermal discomforts; of shortness of breath; of sundry dangers from accidents; free, finally, of the mathematic probability of death a number of years, perhaps, before their time were they of normal weight. Does this fact not mean much?

But, after all, the problem for the portly multitude of men and of the all-too-"motherly"'(?) multitude of women is one of general essential expediency pluis human personality itself! To be fat is grossly inexpedient if only the people knew it, but to conquer the fatness, humorous index of ignorance or sensuality for the most part, is to rise thereby to the full stature of the human, fashioned in the godlike image of superman. The victory is easily attained when conditions are not too adverse, and it is one which tends to satisfy the vanity or the pride in the dignity of the human form; it augments efficiency and tends to the prolongation of one's years. It truly is strange that still so few effectively realize these things. Who is the good twentieth-century prophet that, in tones which all may hear, will proclaim the wrong, its utter needlessness, and the manner, often easy enough, of its righting?

The treatment of obesity is an important thing to consider in the theory and the practice of physical education. Fat comes in mechan- 
cially and chemically in many diseases, especially in relation to the heart; here the presence of fat is an impediment and hindrance, as well as a cause of many disturbances in the organism.

The objection to exercise during the process of digestian in the stomach, is that it brings on a general muscular congestion, taking an excess of blood at the expense of the stomach. It is wrong to exercise violently immediately after a meal, because the muscles would then use the blood which should be in the stomach helping to digest the food. (Gently jolting exercises, such as sauntering, help digestion.) On the other hand, exercise within two or three hours after a meal is at the proper time, for under such conditions the blood is not needed in the process of digestion. We all know the difficulty of even trying to write or to study after a large meal. It does not make so much difference in the case of a small lunch, because the stomach, we may guess, is congested in proportion as it is full of food. By recent research it has been shown that the wall of the stomach constricts closely around the food, so that the more food a person eats the larger functionally is his stomach. Hard exercise after a hearty meal should not be indulged in, while, on the other hand, mild exercises, which tend to jolt the contents of the abdomen, are a distinct aid to digestion. Horseback riding is a fine form of exercise, and is a distinct aid. Walking, and even swinging in a hammock, aids digestion by serving to jolt the contents of the abdomen. The movements of the intestines are both pendular and peristaltic, and are distinctly aided by any mechanical movements of the body. An experiment illustrating the effect of exercise upon nutrition was carried out by Londe in 1860: Two dogs were given a big meal, and immediately afterwards one dog was submitted to violent exercise, while the other was allowed to repose. Two hours later both dogs were killed. It was found that the former had the meal already all in the intestines, entirely undigested, because it had been jolted out of its stomach into the gut by the violent exercise to which it had been submitted. The other dog had the food still in its stomach. The food was well mixed with gastric juice, and digestion was assured. This research shows that the long-standing supposition in regard to the effect of exercise after a hearty meal is a correct one. But see below.

Constipation is an important evil condition with which physical exercise and its lack have close relations. Gant's well-known treatise discusses the effects of exercise on constipation, under seven heads :

First, the heart-action and the circulation are increased by exercise, and any increase in these benefits constipation, because the processes of absorption, nutrition, and elimination are all increased by an increase in the circulation. An increase in the circulation through the intestines hastens the processes of absorption and of nutrition, and the elimination through the kidneys. Many people do not realize what an important factor constipation is in their general health, and of how they can be constipated and yet have movements of the bowels every day. There may be accumulations of waste materials in the large intestine that may stay there indefinitely. This sort of constipation may be nearly as bad, in so far as the absorption of toxins is concerned, and the atony of the muscles of the intestines, as any other kind. A case of complete constipation, with no evacuation of the feces, is fatal, but uncommon. Weeks may elapse.

A second effect of general muscular exercise upon constipation is that it brings about an increased oxidation of the fats and the carbohydrates with a correspondingly increased elimination of carbon dioxide. Exercise, by the oxidation of the carbohydrates and the fats taken into the body, through an increased elimination of carbon dioxide, stimulates, chemically, peristalsis in the intestines, thinks Gant. I am not aware that this supposition ever has been confirmed or that it can be shown to be of more than theoretic importance.

A third effect of general muscular exercise upon constipation, or a third method of the action of exercise upon constipation, is seen in an increased power of respiration. This causes a greater demand for oxygen, and this increase in respiration deepens each time the descent of the diaphragm. The diaphragm goes down oftener, further, and harder, and in this way there is a distinct massage carried out on the liver, the gall-bladder, and upon the transverse colon. This is the most important effect of exercise upon constipation. This increased action of the diaphragm, by its massaging effects upon the liver, increases the flow of bile, and increases the peristaltic movements in the intestines by its massage of the transverse colon. Gant shows that exercise also tends to increase antiperistalsis, which is peristaltic action from 
below upward, common in crustaceans, etc., and easily seen, with little trouble, in Daphnia.

A fourth effect of general muscular exercise on constipation is that it tends to soften the refuse matter which has accumulated in the large intestine and in the gut. By the stimulation of the pancreas, of the liver, and of the intestinal wall, the glands which pour their products out into the intestines are stimulated, and anything that serves to stimulate the secretions from the glands will bring about a softening of the feces.

A fifth effect of exercise upon constipation is along the line of a curative effect, in that exercise relieves and also lessens autointoxication. This is a form of poisoning due to some uneliminated matter formed within the body, and in which there is an absorption of various toxins from the large intestine back again into the blood. This matter is what Horace Fletcher objects to so strenuously. He says that if we were to reduce the amount of proteins consumed, we could lessen the number of bacteria in the intestines, and so lessen the amount of toxins absorbed into the blood. These toxins of bacterial origin, when they invade the system through the blood, give rise to headaches and to many indefinite things due to the evil absorp. tion of decomposing substances, called toxins, from the large intestine. Exercise, by stimulating the movements of the large intestine, relieves this state of autointoxication. This autointoxication acts especially upon the nervous system of the individual concerned. When such a condition is present, his system, upon being relieved, gives a better chance for the normal action of the intestines. We have a sort of reflex action, in that the lessening of the toxins present in the blood allows the nervous system to act normally, and also allows its action upon the intestines to be normal, and so, indirectly, stimulates the movements of the gut.

A sixth effect of general muscular exercise upon constipation is an increase in general muscular strength. This, reflexly and sympathetically, aids the muscular power of the large intestine, and especially of the rectum. I have already shown how intimate is the sympathy between different parts of the musculature of the body. Anything that stimulates the skeletal muscles also affects the vegetative smooth muscles in all parts of the body in a more or less indirect way. The process of defecation concerned in the discharge of the feces is partly a voluntary and partly an involuntary process. It is partly a voluntary process in that is is aided by the abdominal walls. If the abdominal walls have been strengthened by exercise, they can exert a prompter and a harder effect, and so aid defecation.

The seventh effect of general all-round exercise upon constipation is an increased power in the peristaltic movements of the intestines, by a tonic stimulation of the intestinal nerves.

These seven principles are very important as applied to the condition known as constipation. Constipation is a very common condition, so these seven principles have an added value for every teacher of physical training. Many people suffering from constipation consult teachers of physical education. They think, rightly, that they may help them, as they consider their trouble not serious enough to warrant their consulting a physician. This condition is particularly prevalent among the women, in whom, especially, constipation is a matter of great practical detriment, for it can be the source of numerous ills. Massage of the abdomen is beneficial in some cases of extreme constipation, and in fact anything is beneficial that will increase the movements of the intestines.

Sugar. A few words about sugar as a food for the muscles. There is a research in this connection carried out on two schoolboys, aged respectively seventeen and nineteen. Both had the same practice every day, that is, rowing, and they practised two hours daily for two months, and then entered for the races. They were found to be overtrained, and the doctor fed them much sugar. They had as much sugar as they wished, sometimes eating as much as five ounces just before beginning their daily exercise with the oars. Immediately all signs of overtraining began to be abolished, and the result came in about three days from the time that the eating of sugar was advised. They entered the race and won, over a large number of antagonists who had not eaten any sugar. This demonstrates one use of sugar as a food for the muscles.

The ordinary sugars are glucose (grape sugar, dextrose), cane sugar, beet sugar, maple sugar, and levulose-a sugar abundant in figs, dates, and raisins. In practice, we would include sweet chocolate in this list, and we must deplore the strength of the prejudice against glucose.

Some years ago, Harley found that the daily 
consumption of seventeen and one-half ounces of sugar, more than one pound, daily, increased the power of his muscular work from 61 to $76 \%$. A person daily consuming that amount of sugar would not get fat if he exercised enough to use it up. The maximum effect of the sugar taken in the above-cited illustration was in about two hours after it had been eaten. This same research was gone over by Schumberg, and the results were confirmed by him. Those results were that after eating sugar there is an acute and a marked increase in the power of work. As we know now, all the army diets contain a considerable amount of sugar. "Chocolates," etc., are ordered by the ton for the consumption of the army, and are part of the regular ration practically, if not technically. Queen Victoria of England at one time sent a half-pound of sweet chocolate to every British soldier in South Africa. Since that time candy has been included in the diet of every army in the world, especially in the form of chocolate. This chocolate is given to the army and to the navy on the basis that it is a concentrated and first-class food for physical exercise. Its calory value is per weight-unit more than five times that of lean beef, and it is not hard to digest, save to alimentary canals weak in fat digestion.

The fact that the maximum strengthening effect of sugar taken as a food comes in about two hours has been discovered empirically by many people on their own account, as well as by Harley.

Sugar, then, is an important and an immediate source of muscular strength, because it is metabolized easily in the tissues of the body and glycogen is made from it. Practically, then, it is only necessary for the blood to receive the digested sugar and to take it to the muscles, where it is immediately turned to glycogen and serves as the chief food of the muscle fibers. These facts in regard to sugar are something not very new and yet of recent development in their application. Twenty-five years ago there was not a trainer who would feed candy to a training squad.

A few words about training diet. We shall see that there is really nothing very special or peculiar about a training diet. It is not scientific to adapt the diet qualitatively to the kind of work a person is going to do, but it is necessary to adapt the diet somewhat quantitatively.

The training diet (a man or woman of athletic, or very active vocational, habits is "in train- ing") should be ample, but not excessive in amount. I am quite sure that some training diets, extravagant in amount, are far excessive especially in the matter of lean flesh meat. On the other hand, the training diet should contain enough flesh meats, because meat, more than anything else, directly restores the wasting muscles. Sugar supplies the energy of the muscles more quickly and better than any other thing a person can eat. Some fat should be taken. The reason this is so is because the chief part of lean meat which is eaten is made up of the fat muscles of the animal, and the materials to be replaced in the human body are protein and lipoidal.

It certainly behooves college deans, university presidents, academy principals, private school proprietors and administrators, camp food-commissaries, and "such," to see well to it just now that patriotism be not made an excuse for parsi. mony in feeding,- -as a matter important to good health, to efficiency, and to next year's tuitions. Cold, anxiety, and underfeeding all are helping in some institutions toward a most unpatriotic depression of efficiency and towards an increase of phthisis. For example: "We do not need to starve our own people. We have plenty for ourselves, and it is the firm policy of the Food Ad. ministration to retain for our people, by its control of exports, a sufficient supply of every essential foodstuff. We want nobody in our country to eat less than is necessary for good health and full strength, for America needs the full productive power of all its people."

The training diet should include plenty of water. This does not mean that a person needs to wash down his mouthfuls of food with gulps of water. It should be drunk with meals and between meals, but a man or a child should never wash food down mechanically. An abundant supply of water flushes out the tissues of the body and keeps the digestive apparatus loose and active. It is essential to the athlete.

Another characteristic requirement in the "training" diet of any physically very active individual is that it should have nothing in it to cause indigestion or any disturbance of the alimentary canal. Where an athlete is trained "up to the scratch," it would be a decided setback if he were to have an attack of diarrhea for even one day. Such an attack might offset all the training of weeks. For instance, baked beans are not good, owing to the essential oils 
contained in them. These oils are very irritating to some alimentary canals.

Another requirement in a training diet is that there should be more sugar than in the normal diet. Sugar is the best immediate source of muscular energy, but it must not be taken in such large amounts as to produce any disturbance of the digestive apparatus. It is beneficial to eat sugar, sweets and preserves, with a meal or soon after a meal, but never in such large amounts as to disturb digestion.

Another requirement in an ideal training diet is four meals daily instead of three or even two meals a day. With four meals a day, the athlete can digest more, and make better use of more, than if he were taking only three meals a day, and the athlete must be on a high plane of metabolic efficiency. One need not prescribe any particular foods for a training diet, except to define sugar as an essential requirement. Something solid but easily digestible, taken into the stomach late at night, often makes one sleep better, because it takes the blood out of the brain and brings it to the digestive apparatus. If J. F. Shepard's recent contention prove true (that sleep gives cerebral congestion, some other explanation must be sought. The best time to eat fruit is in the morning, and those in training need much of it.

Some of the relations of coffee (and of tea and cocoa) to muscular work: In this connection, take data from a research made by Rivers and Webber, and to. be found in the Journal of Physiology, Vol. 36, p. 46, for the year 1907. They found, first, that caffein (theobromin is similar) increased the power of muscular work; second, they found signs of a double action: (a) an increase in the number of muscular contractions for a short time; $(b)$ an increase in the degree and the extent of muscular contraction, for as long a time as the coffee is taken. This was a laboratory research, done with the ergograph, an instrument for measuring work done in muscular action. Probably their work was done in reference to the skeletal muscles. In general, coffee does away with temporary fatigue of the skeletal or cross-striated muscles. It increases the number of possible contractions for any time, and in any especially fatiguing work it is possible to make more contractions for a short time. The work of Hollingworth at Columbia fully corroborates (and extends) the results of this English research. Coffee imme- diately takes effect, perhaps in about three or four minutes.

Next consider the action of tobacco upon muscular work: Tobacco undoubtedly decreases both the desire and the capability for doing muscular work. There is no doubt of the above statement at all nowadays. Thus, coffee might be of use in a training diet, but it must never be used to such an excess as to keep the individual awake, for sleep sometimes is the most important of all things. In regard to tobacco in a training diet, I should say no tobacco at all (unless in the evening a pipe or two?), at least, none for hours before the contest or special exertion, because tobacco distinctly reduces muscular power, probably by nicotine's depression of the action of the motor end-places of cross-striated muscle.

Practically the same thing is true in regard to the use of alcohol in a training diet. Alcohol lessens the power of muscular (as of intellectual) work, and, physiologically speaking, it does so through the disturbaince of coördination. The kinesthetic impulses are shut off and there cannot be from the cortex a proper coördination of the muscle fibers by the spinal grey. However, there is still a college prejudice in favor of the use of alcohol. This prejudice persists, though it has been demonstrated that its use is an absolute disadvantage in every respect to the athlete. There is here the greatest graft of money-expense to many of the varsity teams in that they are habitually inclined to think it necessary to have champagne! The use of alcohol in a training diet is out of date and one may be very emphatic on that score; snobbery underlies it, in part.

Dean LeBaron Russell Briggs, chairman of the Harvard Athletic Committee, and wise as well as influential, in his recent report well stated an obvious matter (and more politely than the "snobbery" above) as follows :-

"One thing is certain, if when the world is at peace again, and intercollegiate contests are re sumed, we fail to reduce the cost of coaching and training, to inculcate notions less luxurious, and to foster a better understanding of the rela tion between athletics and other interests in life, we shall lose one of the opportunities so dearly bought by this war."

The universities have been prostituting the good name of physical education out of snob bery and cheap notoriety seeking, for the sake of amusing some of their alumni for a few hours 
each year; while the students who need the exereise are grinding themselves into a kyphosis or indolently watching their hired players over. train.

Next, a research on the effect of strychnin on muscular work. It was made by an Englishman, Varrier-Jones, and is to be found in the American Journal of Physiology, 1907. $\mathrm{He}$ found that strychnin somewhat increased the power of muscular work at first. This probably occurred through a stimulation of the reflex centers in the spinal cord. If too much strychnin be taken of course it will tend to lessen your muscular work for good! A second result obtained in this research was that the stimulating effect of strychnin gradually disappears in about three hours' time. In Varrier-Jones's opinion, the action of strychnin is to open wider the synapses of the afferent or ingoing side of the reflex arc. This effect of strychnin was long ago discovered, empirically, by horse-trainers, whose custom it long was to inject strychnia into the horses before the races came off. In ordinary doses, strychnin does not seem to do much harm, the chief danger being that a person will take too much and thereby make himself very nervous.

Strychnin is one of the standard drugs of the world, and it is very widely used as a nerve stimulant, especially as nux vomica. It need not be pointed out that the use of methods and means as artificial as is strychnia is wholly unethical in sport of man or beast. It is mentioned here only because it is a neuromuscular stimulant among stimulants. Adrenin would seemingly have far more appropriate use in a contest of brawn, but whether its use would be ethical or not would be for the judges to determine.

The main thing in a training diet or in a system of training for athletic amateurs, as for amateur or professional athletes, is to see to it that the individuals get plenty of sleep; that they eliminate the use of alcohol and tobacco; and that the training diet contains the essential metabolic requirements, chemically and digestionally.

The second part of our discussion of the effects of exercise on nutrition comes under the head of "too much exercise." There is hardly any limit to all-around normal, outdoor exercise, when the exerciser really is "in training," up to it. The actual recorded maximum was made on a static bicycle in a calorimeter some years ago, and was 14,000 calories of energy a day. This is hard work. For example, most physicians are not expending over 3500 calories of energy an ordinary day at the outside limit. The ordinary and practical limit of the lumberman would be found to be about 7000 or 8000 calories of energy a day. All the conditions requiring a large amount of metabolism (long hours of labor, and oftentimes exposure to the cold and wet and dampness) would demand about this expenditure of energy each working day. The metabolic planes of efficiency must be maintained in order to reach and to maintain the highest limit of motor efficiency. In other words, when the appetite, the supply of food, and its absorptive consumption keep pace with katabolism and excretion, there is scarcely any theoretic limit to the height of the dynamic efficiency which an individual may attain, save that of his actual structure. Plenty of sound sleep and abundant air enable a person to live on a very high plane of efficiency. Do not imagine that one gains anything in undersleeping. Every hour of sleep is worth much to the organism-more than many trainers realize. Athletes in training in the average college and elsewhere tend to approach the plane of efficiency maintained by the lumberman. They are much more liable, however, to have a dangerous overdevelopment of the digestive organs, and so are in more danger of "going stale," because they are living under somewhat abnormal conditions as compared with the industrial lumberman. Athletes in training in college, for example, are pretty sure not to get as much sleep. They are more liable to be tempted to drink, and to smoke excessively, so that, on the whole, they are not comparable in practice, in so far as their plane of efficiency is concerned, with the man doing hard outdoor daily work. The exact data for comparison between the two are lacking, 'but the capable lumberman is certainly our kingly athlete! College athletics might do worse than to use him as the model for royal manly training.

Hypoliposis comes in under this heading of over-exertion. In a recent lecture, "Get Lean and-Homely," the author considered leanness to be occasioned mostly by seven conditions: 1 , innutrition-too little food; 2 , over-exercise of muscle-masses; 3 , general nervousness ; 4 , worrying too much; 5 , the spare-diet habit; 6 , oversecretion of the posterior part of the hypophysis (pituitary); and 7 (perhaps a phase of No. 6?) heredity. Even if over-leanness after mid-age 
be a sign of longevity, the cosmetic considerations are important, especially in women; and lean persons suffer greatly in winter from cold, and are handicapped in certain diseases. A "lucky thirteen" words stand for relief from hypoliposis: general food-abundance, fats, starch, sugar, breads and cereals, storage vegetables, nuts and dried fruits, abundant water, holiday, indolence, easy outdoor life, medical advice, and a warm climate.

A few remarks about the effect of muscular work upon digestibility, meaning thereby the person's ability to digest. In this connection we may bring again to notice a research made by E. C. Wait, published by the U. S. Dept. of Agriculture, and to be found in Experiment Station Bulletin No. 117. The results found in this research are negative, but none the less they are important in that they confirm what many people have long believed. In the first place, he found no difference in the thoroughness of the process of digestion of the food: $(a)$ when the subject was at rest, and, $(b)$ when the subject was walking up and down a hill about four hundred feet high. Common observation corroborates this fact. The second result in this research of Wait's is that he found no constant effect of the climbing on the excretion of nitrogen, which depends upon the relative amount of the intake of food. On the other hand, nerve fatigue and muscle fatigue are apt to cause indigestion, probably from some emotional depression.

Kadegrobow, in his research made on dogs, found that active exercise delayed the secretion of pepsin somewhat. He compared in this research dogs who rested after a big meal with those which then were worked.

Gerhartz's work, found in Pflüger's Archives, July, 1910, was along this same line. He found that food consumption was not increased by exercise, and that the protein katabolism was somewhat lessened! He found that violent exercise before eating did not make the dogs eat more. They got their energy for the work out of the carbohydrate part of their food. This research confirms many others showing that carbohydrates and fats are the important sources of muscular energy. The results of this research are contrary to what one might expect at first, for we would expect that the dog that was working hard would eat more than if he had been resting. The discrepancy undoubtedly is temporary, and psychological rather than metabolic. It is, of course, the common experience that we are distinctly more eager for food and that we eat more of it, after either muscular or mental work. We should develop this conscious guidance.

So much in regard to a few miscellaneous nutritional topics as they are related to physical exertion and exercise. However hard to teach to the world of men and women, assuredly they are of quite basal importance, years on end, in the economic conduct of physiologic life.

\section{THE VENEREAL PROBLEM-THE ARMY VIEWPOINT.}

By Elmore M. McKub, 1st Lr. San. C. N. A.,

Representing the Office of the Surgeon-General of the Army and the War Department Commission on Training Camp Activities.

THE army viewpoint is that between the battleline of Von Hindenburg and that of venereal disease there is a very real connection. The former is a visible, tangible barrier to the Allied advance upon Berlin, the latter a vast hidden barrier within the ranks of the Allied powers. To reach the German capital requires men, and many of them. Men-thousands of men-have already ceased fighting, and been carried in tow, because of venereal disease. This hidden enemy in our midst has long left behind in its wake a spectacle of human devastation, impaired efficiency and wreckage of vitality. Through its ravages many thousands of men have been rendered useless and carried on the liability list through the great battles of the war, through hours when there was a dire need for fighting power.

Three and a half years' observation of the great war have shown this Government that one of its foremost wartime duties is to protect its men from venereal disease. The experiences of the European nations, coupled with those of our own troops on the Mexican border, have been object lessons of singular value. We now know that man-power alone will win the war, and that every unit of man-power that is incapacitated from venereal infection and rendered useless as a fighting force is a greater loss than that of a man killed in action. The former is struck by an enemy from behind before he has had a chance to register an offensive blow, while the latter dies on the firing line, in a grapple with the enemy. 